\title{
Engaging children at-risk through World Vision Australia's Kids Hope Aus. Program
}

\author{
Stephen Larmar \\ Griffith University
}

\begin{abstract}
This paper reports on the findings of a pilot study examining teacher perceptions of the efficacy of the Kids Hope Aus. program. Kids Hope Aus. is an early intervention and prevention program for children at risk of social and academic disengagement. The program emphasises the significance of developing a child's social skills to build resilience and enhance the child's social engagement and general academic achievement within the school setting. The intervention incorporates an adult/child-mentoring framework that serves to ameliorate the effects of specific risk factors that place children at greater risk of vulnerability. The evaluation involved 188 teachers drawn from rural and metropolitan districts in the State of Victoria, Australia, of children who participated in the Kids Hope Aus. program. The findings of the study provide preliminary data that identifies the Kids Hope Aus. program as a cogent intervention framework for fostering greater social inclusion and academic enhancement for young children that can be easily disseminated in regular school communities.
\end{abstract}

Keywords: mentoring, at-risk children, Kids Hope Aus., early intervention and prevention.

Over the last decade there has been an emerging interest in the study of school-based early intervention and prevention programs for children at-risk of later maladjustment (Webster-Stratton, 1998; Walker, Severson, Feil, Stiller, \& Golly, 1998; Dumas, Prinz, Smith, \& Laughlin, 1999; Greenberg, Domitrovich, \& Bumbarger, 2001). A range of programs has been evaluated with numerous studies reporting promising results (August, Realmuto, Hektner, \& Bloomquist, 2001; Conduct Problems Prevention Research Group, 2002; Larmar, Dadds, \& Shochet, 2006). Most school-based programs are administered in the early years given that these forms of intervention have the greatest effect for children with an age range of 4 to 7 years (Kazdin, 1995). Such programs usually include 
specific components that target risk factors including social skills deficits, negative peer association, limited self-control and learning difficulties (Rhodes, 2008; Randolph \& Johnson, 2008; Everhart, 2001; Greenberg, Domitrovich, \& Bumbarger, 1999) as a means of reducing the effects of such risk factors and building resilience and promoting social inclusion.

In the last ten years there has been an emerging interest internationally in child and adolescent mentoring programs (DuBois, Holloway, Valentine, \& Cooper, 2002; Keating, Tomishima, Foster, \& Alessandri, 2002; Barron-McKeagney, Woody, \& D’Souza, 2001; Everhart, 2001). Research into child mentoring practices has focused on the outcomes of mentoring relationships between children and adults (Hamilton \& Hamilton, 1992). Because research in the area of child mentoring is relatively new, there is a dearth of literature to support the impact of mentoring programs for children. Evaluations for mentoring programs such as Big Brothers/Big Sisters have been undertaken to support the efficacy of mentoring for children and young people (Tierney, Grossman, \& Resch, 1995).

While a range of studies has been undertaken that demonstrates the effectiveness of child mentoring for working with general populations of children, few studies exist that support the efficacy of child mentoring programs for at-risk populations. The literature indicates that future research should be directed toward the development and evaluation of mentoring frameworks for at-risk children and families (Jackson, 2002).

Studies by Novotney, Mertinko, Lange and Kelley-Baker (2000), BarronMcKeagney et al. (2001), Everhart (2001) Keating et al. (2002) have shown more recent support for the use of mentoring in supporting vulnerable children. However, there appear to be few school-based evaluations that have been facilitated to determine the effects of child mentoring practices on children more susceptible to ongoing dysfunction including social disengagement (Israelashvili \& Wegman-Rozi, 2005; Portwood, Ayers, Kinnison, Waris, \& Wise, 2005; Roberts, Liabo, Lucas, DuBois, \& Sheldon, 2004; DuBois, Holloway, Valentine, \& Cooper, 2002; Keating, Tomishima, Foster, \& Alessandri, 2002; Barron-McKeagney et al., 2001; Everhart, 2001). Further, no investigation has been undertaken to determine the efficacy of the Kids Hope Aus. program as a framework for engaging at-risk populations.

This paper serves to report on the initial findings of a pilot study to determine teacher perceptions of the efficacy of the Kids Hope Aus. program. A description of the methodology employed for the teacher evaluation is included, as well as outcome data that lends preliminary support for the use of child-mentoring as a means of engaging atrisk children and reducing the effects of school-based risk factors that place children at greater risk of academic failure and social exclusion. Finally, the paper identifies areas for future research in child mentoring for at-risk children as a means of guiding future research agendas in early intervention and prevention.

\section{Kids Hope Aus. Program}

The Kids Hope Aus. program was originally founded in the U.S.A. in 1993. In 2003 the program was licensed as one of World Vision Australia's domestic programs. The Kids Hope Aus. program is a school-based early intervention and prevention program for atrisk children that utilises adult-child mentoring as a means of providing additional 
support for vulnerable children in order to promote social inclusion and academic success.

The intervention design is built around a number of distinct features. The first feature involves schools interested in the facilitation of the Kids Hope Aus. program contacting World Vision Australia to assist in the matching of the school community with a local church group who have trained volunteer mentors to engage in the intervention. All mentors recruited from churches involved in the intervention receive intensive training in the program design and the facilitation of the mentoring relationship by a trained facilitator prior to being matched with a suitable child participant. Further, mentors undergo a rigorous screening process that includes mandatory statutory checks to ensure that they hold no record that might pose a potential risk to participating children. Finally, participating mentors are closely monitored within the school context and regularly liaise with key stakeholders including school principals, classroom teachers and Kids Hope Aus. coordinators to ensure that the integrity of the program and the mentoring relationship is maintained.

The second feature involves a preliminary screening process that identifies at-risk children for potential inclusion in the program. The screening process is facilitated by the school principal working in collaboration with the identified child's school teacher. In the first stage of screening, the principal identifies children whose social interactions and/or academic performance in the previous school year deemed them at greater risk for school disengagement. The identification process involves drawing on records relating to the child's academic achievement and/or social interaction within the school context. Following this initial process, the principal then liaises with the child's current teacher in determining the child's suitability for inclusion in the Kids Hope Aus. program. The child's suitability is determined in negotiation with the child's teacher through an assessment of the child's capacity to positively engage in the program. This is often achieved in collaboration with the child's primary parent/caregiver. Once the child has been selected for the program, the principal and teacher work with World Vision staff to coordinate the matching of the child with a suitably screened mentor drawn from a local church community. This process involves assessing the needs of the child as well as the mentor's personality and prior experiences in working with vulnerable children.

The third feature includes the participation of the child and mentor in a sixtyminute face-to-face mentoring session that occurs on a weekly basis throughout the school year. To maintain the integrity of the program design, it is imperative that all participating mentors have the capacity to sustain the mentoring relationship for the entire academic year. The sixty-minute session consists of relationship building activities as well as strategies that provide academic and social support for the child during the mentoring period. Mentors also maintain regular contact with a Kids Hope Aus. coordinator, drawn from the same local church, to ensure the reliability of the intervention design.

The final feature of the Kids Hope Aus. program involves the church's active collaboration with the participant school to assist in the implementation and facilitation of the mentoring process. This collaboration includes regular engagement between the school principal and the church's program coordinator as well as weekly contact between the child's classroom teacher and the designated mentor. 
World Vision Australia's Kids Hope Aus. national managers facilitate the Kids Hope Aus. program across 170 primary school sites throughout Australia; provide training for Kids Hope Aus. program coordinators; and are also responsible for ensuring that the integrity of the program is maintained by regularly liaising with program coordinators to determine the effectiveness of the program's implementation and facilitation across a range of contexts.

\section{Method}

\section{Recruitment and screening}

Participants for the study included 181 teachers working in schools in rural and metropolitan districts in the State of Victoria. The teachers were selected based on their experiences in working with a child who had participated in the Kids Hope Aus. program in the 2006 academic year. All teachers were screened prior to inclusion in the intervention. The following inclusion criteria were utilised to determine participant suitability for the trial: participating teachers needed to have worked as the child participant's classroom teacher for the entire academic year; and the level of child participation - teachers were excluded from the evaluation if the child involved in the intervention did not meet on a weekly basis with their allocated mentor throughout the school year. Prior to the teacher's involvement in the intervention, parental consent was obtained from the identified children receiving the Kids Hope Aus. program.

\section{Evaluation measure}

For the purposes of this investigation the Kids Hope Aus Evaluation Measure was developed by the World Vision Australia Program Evaluation Department to determine teacher perceptions of the impact of the Kids Hope Aus. program on a random sample of children $(n=181)$ who participated in the intervention. The survey was piloted in the year prior to this initial evaluation and adapted based on teacher feedback regarding its utility. This process served to ensure the robustness and trustworthiness of the measure in accurately measuring the variables under investigation. The survey consists of 14 items that examine teacher perceptions at both pre- and post-intervention around three specific domains considered pertinent to the effectiveness of the Kids Hope Aus. program:

- children's general classroom behaviour and social interaction;

- academic achievement; and

- the perceived benefits of the Kids Hope Aus. program for teachers and students.

Each item consists of a 5 point likert scale assessing teacher perceptions pertaining to the variables under investigation. The survey was distributed to 181 teachers of children participating in the program at the conclusion of the school year and rated teacher perceptions of the child's progress, both socially and academically. The survey also served to elicit teacher's perceptions in terms of their experiences relating to the program's implementation into the school context. 


\section{Treatment integrity and process measures of treatment implementation and engagement}

To determine the consistency of mentors meeting with children participating in the program, teachers recruited for the study kept a record of the mentor's level of engagement with the child. To ascertain mentors' levels of engagement, the program coordinators interviewed all mentors to ensure that the mentoring process met with the aims and objectives of the Kids Hope Aus. program which included regular contact with the child over the academic year and the facilitation of specific activities to assist in the promotion of a positive relationship between the mentor and child. Further, the Kids Hope Aus. national coordinators regularly liaised with all program coordinators as well as participating teachers to ensure the integrity of the program's facilitation.

\section{Results}

To determine teacher perceptions of the efficacy of the Kids Hope Aus. program, a paired sample t-test was conducted on all measures pertaining to all participating children's behaviours and academic achievement using SPSS Version 12.0. Through a comparison of pre-intervention scores (derived from teacher perceptions held at the commencement of the school year) and post-intervention scores (perceptions held at the conclusion of the academic year) results were found to be statistically significant at the 0.05 level, for the measures including:

- on task behaviour;

- student self-regulation;

- following direction;

- positive interaction with teachers and other school personnel;

- positive interaction with peers;

- playground behaviour;

- general classroom behaviour;

- motivation for school work;

- reading level;

- mathematics achievement;

- writing achievement; and

- science achievement.

For each measure, the mean scores increased between pre-intervention and postintervention. Table one shows pre-intervention and post-intervention mean scores of the dependent variable used to measure general achievement goals. The following section provides a summary of findings for each general achievement measure.

On task behaviour: For this variable, the paired sample t-test reported a significant difference between pre- and post-scores over the school year, at the 0.05 significance level $(\mathrm{t}=-17.68, \mathrm{df}=270, \mathrm{p}<0.001)$. At pre-intervention the mean score was 2.51 ( $\mathrm{sd}=$ 
1.14) and at post-intervention the mean score was a level of 3.36 (sd =1.12) with a difference between the mean scores of 0.85 .

Self-regulation: Results of the paired sample t-test for this variable revealed a statistically significant difference between pre- and post-scores over the school year, at the 0.05 significance level $(\mathrm{t}=-16.85, \mathrm{df}=265, \mathrm{p}<0.001)$. The pre-intervention mean score was $2.43(\mathrm{sd}=1.10)$, and 3.15 (sd = 1.02) for post-intervention, with a difference of 0.72 .

Following direction: The analysis for this variable revealed a statistically significant difference, at the 0.05 level, between pre- and post-scores $(\mathrm{t}=-13.63$, $\mathrm{df}=271$, $\mathrm{p}$ $<0.001)$. The mean score for pre-intervention was 2.81 (sd $=1.09$ ) and at postintervention the mean score was 3.45 (sd $=0.99$ ), with a mean score difference of 0.64 .

Positive interaction with teacher and other school personnel: The paired sample t-test results revealed a significant difference between pre- and post-scores over the school year, at the 0.05 significance level $(\mathrm{t}=-14.03$, $\mathrm{df}=268, \mathrm{p}<0.001)$. The preintervention mean score was $3.04(\mathrm{sd}=1.14)$ and increased to a mean score of $3.69(\mathrm{sd}=$ 0.96) at post-intervention. The difference between mean scores at pre-intervention and post-intervention was 0.65 .

Positive interaction with peers: For the variable determining changes in Positive Interaction with Peers, the paired sample t-test reported a significant difference between pre- and post-scores over the school year, at the 0.05 significance level $(\mathrm{t}=-13.52$, $\mathrm{df}=$ 273, $\mathrm{p}<0.001$ ). At pre-intervention the mean score was 2.78 ( $\mathrm{sd}=1.11$ ) and at postintervention the mean score was a level of 3.47 ( $\mathrm{sd}=0.95$ ). While the difference was statistically significant at the 0.05 level, the difference between the mean scores was 0.69 .

Playground behaviour: The paired sample t-test on this variable revealed a statistically significant difference at the 0.05 significance level, between scores at preand post-intervention $(\mathrm{t}=-12.97, \mathrm{df}=271, \mathrm{p}<0.001)$. The pre-intervention mean score was 3.07 ( $\mathrm{sd}=1.22)$, and 3.67 (sd = 0.94) for post-intervention. The difference between pre- and post-mean scores was 0.60 .

General classroom behaviour: For the variable General Classroom Behaviour, the paired sample t-test revealed a significant difference between pre- and post-scores over the school year, at the 0.05 significance level $(\mathrm{t}=-12.87$, $\mathrm{df}=271, \mathrm{p}<0.001)$. The preintervention mean score was $3.07(\mathrm{sd}=1.14)$ and increased to a mean score of 3.69 ( $\mathrm{sd}=$ 0.92 ) for post-intervention data. There was a mean score difference of 0.62 between preand post-intervention.

Motivation for school work: The paired sample t-test indicated a significant difference between pre- and post-scores, at the 0.05 significance level, for the variable Motivation for School Work $(\mathrm{t}=-13.13$, $\mathrm{df}=228, \mathrm{p}<0.001)$. The pre-intervention mean score was $2.71(\mathrm{sd}=1.17)$ and $3.41(\mathrm{sd}=1.06)$ at post-intervention. 
Literacy skill: The difference between the pre- and post-mean scores was 0.70 . For the variable of Literacy Skills, pre- and post-intervention scores were significantly different. The paired sample t-test reported a significant difference at the 0.05 significance level $(\mathrm{t}$ $=-10.68, \mathrm{df}=238, \mathrm{p}<0.001)$. At pre-intervention the mean score was 1.68 ( $\mathrm{sd}=0.78$ ) and at post-intervention the mean score was 2.11 ( $\mathrm{sd}=0.90)$. While the difference was statistically significant at the 0.05 level, the mean score difference was 0.43 .

Mathematical skills: The results of the paired sample t-test revealed a significant difference between pre- and post-intervention scores, at the 0.05 significance level $(\mathrm{t}=$ 9.49, $\mathrm{df}=238, \mathrm{p}<0.001)$. At pre-intervention the mean score was 1.75 ( $\mathrm{sd}=0.77$ ) and $2.10(\mathrm{sd}=0.88)$ for post-intervention.

Writing achievement: The difference between the pre- and post-mean scores was 0.35 . For this variable, the paired sample t-test suggested a statistically significant difference, at the 0.05 significance level between pre- and post-scores $(\mathrm{t}=-8.71$, $\mathrm{df}=$ 196, $\mathrm{p}<0.001)$. The pre-intervention mean score was 1.48 (sd $=0.63$ ) and the postintervention mean score was $1.76(\mathrm{sd}=0.65)$. The difference between mean scores at preand post-intervention was 0.28 .

Science achievement: The paired sample t-test results revealed a statistically significant difference between pre- and post-scores over the school year, at the 0.05 significance level $(\mathrm{t}=-3.89$, $\mathrm{df}=53, \mathrm{p}<0.001)$. The pre-intervention mean score was 1.65 (sd $=0.68$ ) and increased to 1.87 (sd = 0.62) for post-intervention data. The difference between the mean scores at pre- and post-intervention was 0.22 .

Table 1: Summary results for $\mathrm{t}, \mathrm{df}$, and pre- and post-intervention means for variables of general achievement goals.

\begin{tabular}{|l|c|c|c|c|c|}
\hline \multicolumn{1}{|c|}{ Measure } & t & df & $\begin{array}{c}\text { Beginning } \\
\text { of School } \\
\text { Year Mean }\end{array}$ & $\begin{array}{c}\text { End of } \\
\text { School } \\
\text { Year Mean }\end{array}$ & $\begin{array}{c}\text { Mean } \\
\text { Differences }\end{array}$ \\
\hline On Task Behaviour & -17.68 & 270 & 2.51 & 3.36 & 0.85 \\
\hline Self-Regulated & -16.85 & 265 & 2.43 & 3.15 & 0.72 \\
\hline Follows Direction & -13.63 & 271 & 2.81 & 3.45 & 0.64 \\
\hline $\begin{array}{l}\text { Interacts Positively with Teachers } \\
\text { and other School Personnel }\end{array}$ & -14.03 & 268 & 3.04 & 3.69 & 0.65 \\
\hline Interacts Positively with Peers & -13.52 & 273 & 2.78 & 3.47 & 0.69 \\
\hline Playground Behaviour & -12.97 & 271 & 3.07 & 3.67 & 0.60 \\
\hline General Classroom Behaviour & -12.87 & 271 & 3.07 & 3.69 & 0.62 \\
\hline Motivation for School Work & -13.13 & 228 & 2.71 & 3.41 & 0.70 \\
\hline Literacy Skills & -10.68 & 238 & 1.68 & 2.11 & 0.43 \\
\hline Mathematical Skills & -9.49 & 238 & 1.75 & 2.10 & 0.35 \\
\hline Writing Achievement & -8.71 & 196 & 1.48 & 1.76 & 0.28 \\
\hline Science Achievement & -3.89 & 53 & 1.65 & 1.87 & 0.22 \\
\hline
\end{tabular}

In order to ascertain whether general achievement goals were significantly different for students matched with a mentor for greater than or less than six months, an analysis of 
means was undertaken utilising the difference between pre- and post-scores for the measures of On Task Behaviour, Self-Regulation, Follows Direction, Positive Interaction with Teachers and other School Personnel, Positive Interaction with Peers, Playground Behaviour, General Classroom Behaviour, Motivation for School Work, Reading Level, Mathematics Achievement, Writing Achievement, and Science Achievement.

On task behaviour: For the variable determining changes in On Task Behaviour, the average difference between pre- and post-scores for students matched with a mentor for less than six months was $0.90(\mathrm{n}=81)$. In contrast, the difference between pre- and postscores for students matched with a mentor for greater than six months was $0.84(\mathrm{n}=89)$. The variation between the mean differences for students matched with a mentor for less than six months and greater than six months was 0.06 .

Self-regulation: The difference between the mean scores for pre-intervention and postintervention, for students matched with a mentor for less than six months, on the measure of Self-Regulation, was $0.82(\mathrm{n}=79)$. The difference between pre- and post-intervention mean scores for students matched with a mentor for greater than six months was 0.74 (n = 85). The deviation between pre- and post-intervention mean scores for students matched with a mentor for less than six months and greater than six months was 0.08 .

Follows direction: This variable revealed a mean difference of $0.68(n=81)$ between pre- and post-scores, for students matched with a mentor for less than six months. For students matched with a mentor for greater than six months, the difference between the mean pre and post-intervention scores was $0.68(n=90)$. There was no variation between the mean differences for students matched with a mentor for less than six months and greater than six months for this measure.

Positive interaction with teacher and other school personnel: The variance between the mean differences for students matched with a mentor for less than six months and greater than six months was 0.11 . The mean difference between pre- and post-scores for students matched with a mentor for less than six months was 0.75 ( $\mathrm{n}=$ 81). The average difference between pre- and post-scores for students matched with a mentor for greater than six months was $0.64(\mathrm{n}=89)$.

Positive interaction with peers: For the variable determining changes in Positive interaction with peers, the average difference between pre- and post-scores for students matched with a mentor for less than six months was $0.73(n=82)$. In contrast, the difference between pre- and post-scores for students matched with a mentor for greater than six months was $0.64(n=90)$. The variation between the mean differences for students matched with a mentor for less than six months and greater than six months was 0.09 .

Playground behaviour: The difference between the mean scores for pre- and postintervention for students matched with a mentor for less than six months was 0.61 (n = 82). The difference between pre- and post-intervention mean scores for students matched with a mentor for greater than six months was $0.63(n=89)$. The deviation between pre- 
and post-intervention mean scores for students matched with a mentor for less than six months and greater than six months, was 0.02 .

General classroom behaviour: This variable revealed a mean difference of 0.61 (n $=81$ ) between pre- and post-scores, for students matched with a mentor for less than six months. For students matched with a mentor for greater than six months, the difference between the mean pre- and post-intervention scores was $0.65(\mathrm{n}=90)$. The variation between the mean differences for students matched with a mentor for less than six months and greater than six months, was 0.04 .

Motivation for school work: The variance between the mean differences for students matched with a mentor for less than six months and greater than six months was 0.03. The mean difference between pre- and post- scores for students matched with a mentor for less than six months was $0.75(n=66)$. The average difference between pre- and postintervention scores for students matched with a mentor for greater than six months was $0.72(n=75)$.

Literacy skills: For the variable determining changes in Literacy Skills, the average difference between pre- and post-scores for students matched with a mentor for less than six months was $0.48(n=70)$. In contrast, the difference between pre- and post-scores for students matched with a mentor for greater than six months was $0.42(\mathrm{n}=89)$. The variation between the mean differences for students matched with a mentor for less than six months and greater than six months was 0.06 .

Mathematical skills: The difference between the mean scores for pre- and postintervention, for students matched with a mentor for less than six months was 0.31 ( $\mathrm{n}=$ 70). The difference between pre- and post-intervention mean scores for students matched with a mentor for greater than six months was $0.38(n=83)$. The deviation between preand post-intervention mean scores for students matched with a mentor for less than six months and greater than six months was 0.07 .

Writing achievement: This variable revealed a mean difference of $0.29(\mathrm{n}=56)$ between pre- and post-scores, for students matched with a mentor for less than six months. For students matched with a mentor for greater than six months, the difference between the mean scores at pre- and post-intervention was $0.20(n=68)$. The variation between the mean differences for students matched with a mentor for less than six months and greater than six months was 0.09 .

Science achievement: The variance between the mean differences for students matched with a mentor for less than six months and greater than six months was 0.42. The mean difference between pre- and post-scores for students matched with a mentor for less than six months was $0.43(\mathrm{n}=15)$. The average difference between pre- and postscores for students matched with a mentor for greater than six months was $0.01(n=13)$. 


\section{Teacher perceptions of the program}

To determine teacher perceptions of the Kids Hope Aus. program on the measures of: benefit to the student; ease of implementation into the school setting; and benefiting a teacher's relationship with the target child, descriptive statistics were employed. In order to ascertain whether there was a significant difference between the teacher's perceptions of the program and year level, a one-way analysis of variance (ANOVA) was undertaken.

Beneficial to the student: For the variable determining whether teachers believed the Kids Hope Aus. mentoring relationship was Beneficial to the student, the majority of teachers, $94.5 \%(\mathrm{n}=260)$, agreed to an extent that the relationship was beneficial. Of these teachers, $66.5 \%(n=183)$ strongly agreed, and $28.0 \%(n=77)$ of teachers agreed that the mentoring relationship was beneficial to the student. 5.5\% $(n=15)$ were uncertain that the relationship was beneficial to the student.

The ANOVA results suggested that, at the 0.05 significance level, there was no significant difference between the year level being taught and perceptions that the Kids Hope Aus. relationship was beneficial to the student $(\mathrm{F}=1.59, \mathrm{df}=6,263, \mathrm{p}=1.51)$.

Ease of implementation: The results for the variable Ease of implementation of the program into the school setting, revealed that the majority of teachers, 94.8\% $(n=257)$ agreed that the program allowed for ease of implementation. The degree to which teachers perceived ease of implementation was $59.0 \%(n=160)$ of teachers agreeing strongly, and 35.8\% ( $n=97)$ of teachers agreeing. $4.8 \%(n=13)$ of teachers reported that they were uncertain that the relationship was beneficial to the student, and $0.4 \%$ of teachers $(n=1)$ disagreed that the program allowed for ease of implementation into the school setting.

The results from the ANOVA suggested a statistically significant difference between year level taught and teacher perceptions that the mentoring program allowed for ease of implementation into the school setting $(\mathrm{F}=2.58, \mathrm{df}=6,259, \mathrm{p}<0.05)$. Post-hoc analysis, employing Tukey's Honestly Significant Difference (HSD), revealed a significant difference in the perception of prep year and fourth grade, as well as fourth grade and fifth grade teachers. Analysis of the means suggested that prep year teachers (mean = 1.26 , sd $=0.45$ ) perceived implementation of the program as easier than fourth grade teachers $($ mean $=1.79$, sd $=0.73)$. Additionally, mean comparisons suggested that fifth grade teachers (mean $=1.30$, sd $=0.54$ ) perceived implementation of the program as easier than fourth grade teachers. Although the analysis reveals a statistically significant difference, the mean scores suggest that prep, fourth and fifth grade teachers agreed, to an extent, that the program allowed for ease of implementation into the school setting.

Benefited the teacher's relationship with the target child: Analysis suggested that for the variable determining whether the program Benefited the teacher's relationship with the target child, $66.8 \%(\mathrm{n}=181)$ of teachers were in agreement that the program benefited their relationship with the student. Of these 181 teachers, $30.3 \%$ ( $\mathrm{n}=$ 82) strongly agreed, and $36.5 \%(n=99)$ of teachers agreed that the program benefited 
their relationship. $29.2 \%(n=79)$ were uncertain, and 3.7\% of teachers $(n=10)$ disagreed that the program benefited their relationship with the target child. $0.4 \%$ of teachers $(\mathrm{n}=$ 1) strongly disagreed that the program benefited their relationship with the target child.

The ANOVA results indicated that there was a statistically significant difference between year level taught and teacher perceptions that the mentoring program benefited their relationship with the target child $(\mathrm{F}=2.30, \mathrm{df}=6,259, \mathrm{p}<0.05)$. Post-hoc analysis, employing Tukey's Honestly Significant Difference (HSD), revealed a significant difference in the perceptions of first and second year teachers, second and fifth year teachers and third and second year teachers. Analysis of the means revealed that grade one teachers (mean $=2.00$, sd $=0.73$ ) perceived the program as benefiting their relationship with the child more than second grade teachers (mean $=2.53$, $\mathrm{sd}=0.73$ ). Grade five teachers (mean $=1.81$ ) perceived the program as benefiting their relationship with the child more than second grade teachers (mean $=2.53$, $\mathrm{sd}=0.73$ ). Analysis of the means also suggested that grade three teachers (mean $=1.90$, $\mathrm{sd}=0.96$ ) perceived the program as benefiting their relationship with the child more than second grade teachers (mean $=2.53$, sd $=0.73$ ).

\section{Areas of student progress and needs for improvement}

To determine the most significant Areas of student progress and needs for improvement, for the domains of student behaviour, academic achievement, and motivation for school, data coding was undertaken. The written responses from teachers were coded into subscales of motivation, behaviour, self esteem, focus, attitude, respect, social skills, literacy, numeracy, listening, academic (general), and all areas. Table two shows the percentage of teacher responses to areas of student progress and need for improvement, utilizing these subscales.

The largest areas of progress, in the context of student's behaviour, academic achievement and motivation for school, was student's self-esteem (26.30\%), and student's social skills (23.20\%). Teachers' perceptions of the biggest need for improvement, were identified as social skills (27.2\%) and self-esteem (14.5\%).

Table 2: Teachers' responses to areas of students' progress and need for improvement (\%)

\begin{tabular}{|l|c|c|}
\hline \multicolumn{1}{|c|}{ Subscale } & $\begin{array}{c}\text { Areas of Progress } \\
\text { (\%) }\end{array}$ & $\begin{array}{c}\text { Need for } \\
\text { Improvement } \\
(\mathbf{\% )}\end{array}$ \\
\hline Motivation & 13.80 & 9.80 \\
\hline Behaviour & 10.90 & 9.10 \\
\hline Self-esteem & 26.80 & 14.90 \\
\hline Focus & 8.00 & 11.60 \\
\hline Attitude & 12.00 & 4.00 \\
\hline Respect & 5.10 & 1.80 \\
\hline Social Skills & 23.20 & 27.20 \\
\hline
\end{tabular}


Table 2: (Continued)

\begin{tabular}{|l|c|c|}
\hline \multicolumn{1}{|c|}{ Subscale } & $\begin{array}{c}\text { Areas of Progress } \\
\text { (\%) }\end{array}$ & $\begin{array}{c}\text { Need for } \\
\text { Improvement } \\
\text { (\%) }\end{array}$ \\
\hline Literacy & 9.10 & 8.00 \\
\hline Numeracy & 3.60 & 5.80 \\
\hline Listening & 0.70 & 2.20 \\
\hline Academic (general) & 3.30 & 9.80 \\
\hline All areas & 2.50 & 1.10 \\
\hline
\end{tabular}

Motivation: Responses for this subscale included the comments: motivation to attend school, attendance, motivation for academic achievement, and organisation skills. $13.80 \%(n=38)$ of teachers identified motivation as an area of student progress. $9.80 \%$ $(n=27)$ of teachers identified motivation as an area in need of improvement.

Behaviour: The subscale of Behaviour incorporated teacher comments such as; playground behaviour, self control, completing set work, and disruptive behaviour. The proportion of teachers who identified behaviour as a large area of student progress was $10.90 \%(n=30) .9 .10 \%(n=25)$ of teachers identified behaviour as one of the biggest areas in need of improvement for the target child.

Self-esteem: Data coded in this subscale included responses of self worth, confidence to have a go, confidence in ability, and confidence (general). The percentage of teachers who considered self-esteem to be one of the biggest areas of progress for the student was $26.30(n=74)$. The percentage of teachers who identified self-esteem as one of the biggest needs for improvement was $14.90(n=41)$.

Focus: Within the subscale Focus were teacher responses such as application to school work, on task behaviour, and concentration. Focus was identified by $8.00 \%(\mathrm{n}=22)$ of teachers as one of the largest areas of student progress. $11.60 \%(n=32)$ of teachers identified responses classified into the subscale of focus, as an area of need for improvement for the target child.

Attitude: Responses for this subscale included the comments: willingness to engage in activities, willingness to participate, positive attitude, effort to class work, motivation to write and attitude to school work. $12.00 \%(n=33)$ of teachers identified attitude as an area of student progress and $4.00 \%(n=11)$ of teachers identified attitude as an area in need of improvement.

Respect: The subscale of Respect incorporated teacher comments such as: respect for others, interacts with adults in a more positive manner, interaction with teachers and other school personnel, interaction with female role models, and respecting adults. The 
proportion of teachers who identified respect as a large area of student progress was $5.10 \%(n=14) .1 .80 \%(n=5)$ of teachers identified respect as one of the biggest areas in need of improvement for the target child.

Social skills: Data coded into this subscale included responses of positive interaction with peers, social interaction, emotional intelligence, cooperation, risk taking, self control, positive interactions, emotional control, relationships, sharing, self monitoring, connectedness with peers, discusses feelings, tantruming, conflict, emotional coping strategies, conversation skills, tolerance of others, temper control, extending friendships, understanding annoying behaviour, calling out, anger management, social awareness, connectedness to others, group participation, and communication skills. The percentage of teachers who considered social skills to be one of the biggest areas of progress for the student was $23.20(n=64)$. The percentage of teachers who identified social skills as one of the biggest needs for improvement was $27.20(n=75)$.

Literacy: Incorporated in the subscale of Literacy were teacher responses such as reading comprehension, language, literacy, handwriting, language development, reading and writing. Literacy was identified as one of the largest areas of student progress by 9.10\% $(n=25)$ of teachers. $8.00 \%(n=22)$ of teachers identified responses classified into the subscale of literacy, as an area of need for improvement for the target child.

Numeracy: Responses for this subscale included the comments: numbers, maths, number facts and telling time. $3.60 \%(\mathrm{n}=10)$ of teachers identified numeracy as an area of student progress. 5.80\% $(n=16)$ of teachers identified numeracy as an area in need of improvement.

Listening: The subscale of Listening incorporated teacher comments such as: listening, listening to the speaker, listening to instructions, and listening attentively. The proportion of teachers who identified listening as a large area of student progress was $0.70 \%(n=2)$. $2.20 \%(n=6)$ of teachers identified listening as one of the most significant areas in need of improvement for the target child.

Academic (general): This subscale incorporated teacher comments such as academics, general academics, academic work, general comprehension, problem solving skills, academic progress and academic attention. The proportion of teachers who identified academic (general) as a large area of student progress was $3.30 \%(\mathrm{n}=9)$. $9.80 \%(n=27)$ of teachers identified academic (general) as one of the significant areas in need of improvement for the target child.

All areas: Incorporated into the subscale of All areas were teacher responses such as: all areas have made progress, and improvement in all areas. All areas was identified as one of the largest areas of student progress by $2.50 \%(n=7)$ of teachers. $1.10 \%(n=3)$ of teachers identified responses classified into the subscale of focus, as an area of need for improvement. 


\section{Discussion}

The purpose of this investigation was to determine teacher perceptions of the efficacy of the Kids Hope Aus. program as an early intervention and prevention program for vulnerable primary school-aged children. The results of this initial evaluation would indicate that the Kids Hope Aus. program provides a cogent framework for engaging atrisk children and ameliorating identified risk factors that impact upon a child's social and academic engagement within the school context. For those children involved in the program, teachers reported improvements in general classroom behaviour, academic achievement and greater social inclusion within the school context. Teachers also indicated that the Kids Hope Aus. program design provided a framework that enabled the program to be readily administered within a regular school context.

While this evaluation has identified how the Kids Hope Aus. program has led to positive gains for children as demonstrated through children's academic achievement and behaviour, it is important to note that the evaluation process was limited in scope. The initial evaluation measure formulated for the purposes of this study was confined to general information pertaining to child participants' academic and social success. The conclusions drawn from this evaluation would indicate that, while the Kids Hope Aus. program has merit in terms of its provision of remedial support for vulnerable young children, more rigorous investigation needs to be undertaken to facilitate a more in depth understanding of how the intervention serves to build resilience in children.

\section{General behaviour}

With regard to teacher's perceptions of the Kids Hope Aus. program's impact on student's general behaviour, the analysis revealed a statistically significant difference between pre- and post-measures of:

- on task behaviour;

- self-regulation;

- follows direction;

- positive interaction with teachers and other school personnel;

- positive interaction with peers;

- playground behaviour;

- general classroom behaviour; and

- motivation for school work.

Based on the findings drawn from the evaluation it would seem that students involved in the Kids Hope Aus. program appeared to improve in their general classroom behaviour and motivation to engage in schoolwork over the course of the academic year. There was a significant trend towards students exhibiting more frequent on task behaviours towards the conclusion of the school year. Teachers also indicated that students who were matched with a mentor improved in their capacities to self-regulate. An improvement in students' abilities to follow teacher direction was also reported which may have also contributed to the change in teacher perceptions relating to mentored student's capacities to interact positively with teachers, the student's peers and other school personnel. 
Teachers also acknowledged a shift in the student's playground behaviours, indicating that significant improvements were gained during the school year.

\section{Academic achievement}

In terms of teacher perceptions regarding the influences of the Kids Hope Aus. program on student academic achievement the analysis revealed a statistically significant difference between pre- and post-measures of:

- reading level;

- mathematics achievement;

- writing achievement; and

- science achievement.

The evaluation findings would indicate that mentored children improved significantly in terms of their general academic achievement. In terms of children's literacy skills significant gains were reported which would indicate that the Kids Hope Aus. program served to assist students in improving their literacy skills. This was also the case in the area of mathematics achievement for students involved in the program. In terms of children's writing achievements a significant improvement was also found in mentored children over the school year. Students' achievements in science seemed to improve over time, providing some evidence of the intervention's effects for participating children.

For both general behaviour and academic achievement the scores increased between pre- and post-intervention, for each measure. These findings suggest that the Kids Hope Aus. program positively affected general behaviour and academic achievement for students involved in the program. It should be noted however, that the differences between the mean values for each measure at pre- and post-intervention were only small. The average difference between pre- and post-means for all measures was 0.56 (range $=0.85$ to 0.22 ). As such, these findings should be interpreted with caution .

There was no significant difference on the measures reporting on changes in behaviour and academic achievement for children who were mentored for greater than six months in contrast to children who were mentored for less than six months. The mean variance between pre- and post-intervention scores, for students mentored less than six and greater than six months, was minimal at a level of 0.09. On measures including On Task Behaviour, Self-Regulation, Following Direction, Positive Interaction with Teachers and other School Personnel, Positive Interaction with Peers, Playground Behaviour, General Classroom Behaviour, Motivation for Schoolwork, Reading Level, Mathematics Achievement, and Writing Achievement, all measures revealed mean differences of less than 0.12 . This suggests that there was no significant difference between general achievement goals and periods of mentor matching.

It should be noted that the findings that suggest that there was no significant difference between measures of general behaviour and academic achievement and periods of mentor matching should be interpreted with caution. Of the 276 who completed questionnaires, this item was not answered by 104 respondents which may suggest that this finding may not represent the entire sample. 
While significant improvements were reported by teachers in areas including general behaviour and academic achievement, there may have been a potential Hawthorne effect (Babbie, 2007) as a result of the teacher's engagement in the evaluation. That is, participating teachers may have developed a biased perspective concerning their perceptions of children's behaviour and academic achievement as a result of their interest in and support for the Kids Hope Aus. program. Utilising additional measures that could have been completed by another member of the school community or the child's mentor may have given weight to the evaluation's conclusions.

It should also be noted that, although the Kids Hope Aus. program led to positive gains, it cannot be assumed that behaviour change and improved academic performance in participating children can be attributed solely to the program's effects. Such in depth analysis of influencing factors beyond the confines of the intervention design was not possible given the limitations of the evaluation. However, the findings drawn from this initial pilot study do suggest that Kids Hope Aus. did account for behaviour change and increased academic engagement in participating children.

According to the findings derived from the teacher responses relating to teacher perceptions of the Kids Hope Aus. program, results were promising, revealing overarching perceptions that acknowledge the benefits of the program for at-risk children.

\section{Teachers' perceptions of program benefits}

In terms of the benefits for children derived from the mentoring relationship facilitated by the Kid Hope Aus. program, the majority of teachers (94.5\%) reported that the mentoring relationship was beneficial to the participating child. As indicated in an earlier section of the report, there were also no significant correlations between teacher perceptions and the year level taught. This would suggest that the majority of teachers representing all grade levels perceived the mentoring relationship as benefiting the target child.

Based on the findings relating to the Kids Hope Aus. program's utility, a high proportion of teachers (94.8\%) reported that the program allowed for ease of implementation into the school setting. However, there was a slight variance in perceptions across year groups. Further investigations should consider appropriate means to capture information relating to the program's utility in order to better comprehend potential barriers to participation and engagement for classroom teachers at various year levels.

In terms of the Kids Hope Aus. program's benefits to the teacher/student relationship, $66.8 \%$ of teachers indicated that the intervention served to benefit the teacher's relationship with the student. $29.2 \%$ of teachers were uncertain as to whether the program benefited their relationship with the target child. Further analysis revealed a statistically significant difference between teacher's perception that the program benefited their relationship with the student and year level. A variance also existed in terms of the perceived benefits to the teacher/ student relationship across year groups which calls for further investigation to more fully understand underlying reasons for this trend.

Teacher reports focusing on students' progress throughout the academic year suggest that the Kids Hope Aus. program enhanced the self-esteem and social skills of 
children and positively impacted upon the behaviour, attitude and motivation of participants, promoting greater social inclusion within the school environment.

\section{Strengths and limitations}

A number of strengths was evident in this study that warrants attention. First, the large sample of teachers recruited for the investigation enabled the researchers to draw on data from a broad community sample. Second, the homogeneity of participating schools gave weight to the teachers' responses increasing the validity of the data. Third, mentors involved in the intervention demonstrated high treatment integrity throughout the evaluation period. Fourth, participating school and administrative staff were highly supportive of the intervention and its evaluation allowing for the successful facilitation and implementation of program and evaluation processes. Such strengths provide support for community based interventions designed to ameliorate risk factors commonly identified in school-aged children.

There were also some limitations identified that require consideration. First, data drawn from the sample was limited to teacher perceptions as derived from the Kid's Hope Aus. Evaluation Measure. The inclusion of multiple measures that included qualitative data collection techniques would have served to strengthen the research findings by drawing on a broader range of perspectives regarding the intervention's impacts. However, it should be noted that the nature of this investigation was limited to a pilot study and as such was focused on quantitative data derived from the Kids Hope Aus. Evaluation tool. Second, school administrators were involved in screening child participants for inclusion in the program. Further screening measures would have provided greater rigour in terms of the process of participant inclusion. Third, the lack of a control group in the overall design of the study limited findings to a select group of participants which in turn influenced the robustness of the evaluation's outcomes.

\section{Future Directions}

Based on the Kids Hope Aus. program pilot study, a number of recommendations can be made to direct future research. First, investigations of alternative mentoring programs need to be facilitated that include rigorous methods of testing to determine the effects of such programs for at-risk children, particularly within the Australian context. Second, future research in early intervention and prevention needs to consider the influences of multiple factors beyond the school setting that increase the child's susceptibility to future maladjustment. Finally, further consideration needs to be given to the impacts of homeschool partnerships in ameliorating some of the potentially deleterious effects of specific risk factors evident within the home and school contexts.

\section{Conclusion}

This paper has presented the findings of a pilot study to determine the effectiveness of the Kids Hope Aus. mentoring program based on teacher perceptions of the program and its impacts on student engagement. An initial description of the intervention was delineated to communicate the underpinning rationale for the program. Key processes associated 
with the intervention were also outlined including the central emphasis of the program on the facilitation of a mentoring relationship between a trusted adult and identified at-risk child. Data drawn from the investigation was also reported to identify teacher perceptions of the efficacy of the program in improving child participants' academic achievement and social engagement as a means of promoting greater social cohesion within the school context. Finally, strengths and limitations of the study were identified as well as areas for future research in child mentoring practices.

\section{References}

August, G.J., Realmuto, G.M., Hektner, J.M., \& Bloomquist, M.L. (2001). An integrated components preventative intervention for aggressive elementary school children: The early risers program. Journal of Consulting and Clinical Psychology, 69 (4), 614-626.

Babbie, E. (2007). The Practice of Social Research (12th Ed.). U.S.A.: Wadsworth Publishing.

Barron-McKeagney, T., Woody, J.D., \& D’Souza, H.J. (2001). Mentoring at-risk Latino children and their parents: Impacts on social skills and problem behaviors. Child and Adolescent Social Work Journal, 18, (2), 119-136.

Conduct Problems Prevention Research Group (2002). Evaluation of the first 3 years of the fast track prevention trial with children at high risk for adolescent conduct problems. Journal of Abnormal Child Psychology, 30 (1), 19-35.

DuBois, D.L., Holloway, B.E., Valentine, J.C., \& Cooper, H. (2002). Effectiveness of mentoring programs for youth: A meta-analytic review. American Journal of Community Psychology, 30, (2), 157-197.

Dumas, J.E., Prinz, R.J., Smith, E.P. \& Laughlin, J. (1999). THE EARLY ALLIANCE prevention trial: An integrated set of interventions to promote competence and reduce risk for conduct disorder, substance abuse, and school failure. Clinical Child and Family Psychology Review, 2, 37-53.

Everhart, K.D. (2001). Promoting resiliency in at-risk children through an integrated adult-child mentoring and character development program: An analysis of mentoring strategies with regard to outcomes. Psychology/Dissertation Abstracts International: Section B: the Sciences \& Engineering. Vol 62(2-B), Aug 2001, 1075, US: Univ Microfilms International. South Carolina, U.S.A.

Greenberg, M.T., Domitrovich, C., \& Bumbarger, B. (2001). The prevention of mental disorders in school-aged children: Current state of the field. Prevention and Treatment, 4, (1) 1-62.

Greenberg, M.T., Domitrovich, C., \& Bumbarger, B. (1999). Preventing Mental Disorders in School-Age Children: A Review of the Effectiveness of Prevention Programs. USA: Pennsylvania State University.

Hamilton, M., \& Hamilton, S. (1992). Mentoring programs: Promise and paradox. Phi Delta Kappan, 73, 546-550.

Israelashvili, M., \& Wegman-Rozi, O. (2005). Mentoring at-risk preschoolers: Lessons from the A.R.Y.A project, The Journal of Primary Prevention, 26, (2), 189 - 201.

Jackson, Y. (2002). Mentoring for delinquent children: An outcome study with young adolescent children. Journal of Youth and Adolescence, 31, (2), 115-122. 
Keating, L.M., Tomishima, M.A., Foster, S., \& Alessandri, M. (2002). The effects of mentoring program on at-risk youth, Adolescence. 37, (148), 717-734.

Larmar, S.A., Dadds, M.R., \& Shochet, I. (2006). Successes and challenges in preventing conduct problems in Australian preschool-aged children through the Early Impact (EI) program. Behaviour Change, 23, (2), 121-137.

Kazdin, A.E. (1995). Conduct disorders in childhood and adolescence. Developmental Clinical Psychology and Psychiatry, Vol 9. London: Sage Publications.

Novotney, L.C., Mertinko, E., Lange, J., \& Kelley Baker, T. (2000). Juvenile mentoring program: A progress review. Juvenile Justice Bulletin. September 2000. U.S.A: U.S. Department of Justice.

Portwood, S., Ayers, P., Kinnison, K., Waris, R., \& Wise, D. (2005). Youth Friends: Outcomes from a school-based mentoring program. Journal of Primary Prevention, 26, 129 - 145.

Randolph, K.A., \& Johnson, J.L. (2008). School-based mentoring programs: a review of the research. Children and Schools, 30, (3), $177-185$.

Rhodes, J.E. (2008). Improving youth mentoring interventions through research-based practice. American Journal of Community Psychology, 41, 35 - 42.

Roberts, H., Liabo, K., Lucas, P., DuBois, D., \& Sheldon, T.A. (2004). Mentoring to reduce antisocial behaviour in childhood, British Medical Journal, 328, 512 514.

Tierney, J.P., Grossman, J.B., \& Resch, N.L. (1995). Making a difference: An impact study of Big Brothers/Big Sisters. Philadelphia, PA: Public/Private Ventures.

Walker, H.M., Severson, H.H., Feil, E.G., Stiller, B., \& Golly, A. (1998). First step to success: Intervening at the point of school entry to prevent antisocial behavior patterns. Psychology in the Schools, 35, (3), 259-269.

Webster-Stratton, C. (1998). Preventing conduct problems in head start children: Strengthening parenting competencies. Journal of Consulting and Clinical Psychology, 66, (5), 715-730.

\section{Biographical Note}

For the past fifteen years Stephen Larmar has worked in the fields of Education and Psychology. He is currently working as a full-time senior lecturer at Griffith University in the School of Human Services and Social Work where he teaches introductory psychology and counselling. The emphasis of Stephen's research focuses on early intervention and prevention for children and families at-risk. 